\title{
Enunciación
}

http://revistas.udistrital.edu.co/ojs/index.php/enunc

\section{La multimodalidad del cómic: una experiencia de lectura de imágenes en los primeros grados escolares}

\author{
The multimodality of the comic: An experience of images reading in the first \\ school grades
}

\author{
Adriana Matilde Chacón Méndez
}

Para citar este artículo: Chacón, A. M. (2015). La multimodalidad del cómic: una experiencia de lectura de imágenes en los primeros grados escolares. Enunciación, 20(2), pp. 190-206.

Recibido: 20-octubre-2015 / Aprobado: 30-noviembre-2015

\section{Resumen}

El presente artículo es el resultado de la investigación "Lectores de cómics: constructores de sentido", una experiencia de lectura de imágenes que desde la perspectiva semiótica favorece la construcción de sentido de lo que se lee y posibilita la producción escrita en el contexto escolar. Esta pesquisa se realizó con estudiantes del grado segundo, en clase de lenguaje, en una institución educativa pública de Bogotá. El proyecto se desarrolló a través del diseño metodológico de la sistematización de experiencias que correlaciona los procesos de enseñanza y aprendizaje a través de prácticas pedagógicas que responden a nuevos modos de leer nuevos lenguajes, nuevas formas de representar y configurar la cultura.

Palabras clave: lectura multimodal, lectura de imágenes, multimodalidad del cómic, perspectiva semiótica, sistematización de experiencias.

\begin{abstract}
This paper is the result of the research project "Comics readers: builders of meaning" an experience of images reading that, from a semiotic perspective, helps to construct the meaning of what the students read, and to facilitate their written production at school. This research was performed with second grade students in language class at a public school at Bogota. The project was developed through the methodological design of systematization of experiences that correlates the processes of teaching and learning through pedagogical practices that respond to new ways of reading new languages, new ways to represent and configure culture.
\end{abstract}

Keywords: comic multimodality, image reading, multimodal reading, semiotic perspective, systematization of experiences.

1 Licenciada en Educación Básica con énfasis en Humanidades y Lengua Castellana de la Universidad la Gran Colombia, candidata a Magíster en Pedagogía de la Lengua Materna de la Universidad Distrital Francisco José de Caldas. Docente de básica primaria en el Colegio Enrique Olaya Herrera I.E.D. Correo electrónico: matista.85@gmail.com 


\section{INTRODUCCIÓN}

La enseñanza de la lectura es un objetivo fundamental de la educación en los primeros grados escolares y ha perdurado desde hace mucho tiempo como proceso de alfabetización convencional, ya que se considera indispensable para acercarse al conocimiento de todas las áreas del saber que plantea el currículo. Aprender a leer no es exclusividad de la escuela y tampoco se determina por el dominio lingüístico que se tiene; sin embargo, además de ser funcional para la vida escolar también es un aprendizaje necesario para configurarse en la sociedad, acceder a otros conocimientos de la cultura y participar de actos de comunicación; como lo plantea Cassany (2009) en los nuevos estudios de literacidad, el uso de la lectura se da bajo un propósito social. Esto evidencia que el aprendizaje de la lectura requiere del desarrollo cognitivo, social y cultural que le permite al ser humano interactuar en los ámbitos personal, escolar, profesional y social, que lo constituyen.

De ello resulta como eje central para esta investigación la lectura de imágenes desde una perspectiva semiótica, ya que está compuesta por todos aquellos sistemas de signos y sus relaciones para comprender la realidad. En este sentido, Kress (2003) afirma: "[...] ya no se puede tratar el lenguaje oral y escrito como los únicos y principales medios de representación y comunicación" (p. 49). Esta es una razón para que en el escenario educativo los docentes reflexionen y replanteen la concepción sobre la enseñanza de la lectura que se trabaja en las prácticas pedagógicas desde los primeros grados escolares. Además, se pretende analizar los procesos de alfabetización que se enseñan en la escuela y las implicaciones de alfabetizar a los educandos en otros lenguajes como las imágenes, la televisión, las tecnologías digitales, entre otros.

Estos planteamientos generales sobre la lectura llevan a reflexionar la práctica pedagógica sobre nuevas y tradicionales formas de leer, vinculadas al proceso de enseñanza y aprendizaje; por tanto, este trabajo investigativo inicia con la indagación de las concepciones y metodologías empleadas por algunos docentes de grado primero, frente a la lectura de imágenes, el nivel de apropiación que tienen los estudiantes sobre este sistema de signos en el aula y los hallazgos acerca de este objeto de estudio en el interior de mi práctica pedagógica. Los resultados de este estudio dieron origen a la investigación "Lectores de cómics: constructores de sentido" que se desarrolla a través de la sistematización de la experiencia de lectura de imágenes, específicamente del cómic, en el primer grado de básica primaria de un colegio público de Bogotá.

En el análisis de la observación del contexto se evidencia como problema de investigación la ausencia de procesos de enseñanza de lectura con textos no verbales; para este trabajo en particular, la lectura de imágenes, ya que se enfatiza en prácticas de aprendizaje del lenguaje verbal. Así, las imágenes en el aula de clase son utilizadas como un instrumento para el aprendizaje de la lectura de las letras del alfabeto, como lo ejemplifican frecuentes prácticas donde se sustituye la imagen por la palabra o el empleo de la imagen para reforzar alguna temática del plan de estudios. En consecuencia, se plantea como pregunta de investigación: ¿De qué manera el desarrollo de las experiencias de lectura de imágenes como el cómic favorecen la formación de niños lectores en el primer grado de básica primaria?

De la definición de la problemática se proyecta como objetivo general de investigación favorecer la formación de lectores en primer grado de básica primaria, a partir de una experiencia de lectura de cómics. Para este propósito se trazan como rutas específicas diseñar e implementar la experiencia lectora mediante talleres pedagógicos, la cual es sistematizada durante y después de la práctica. Del resultado de este análisis se genera la resignificación de las acciones pedagógicas de la docente sobre la enseñanza de la lectura y los aspectos teóricos y didácticos que implican formar niños lectores. 
Incluir la enseñanza de la lectura de cómics en la práctica pedagógica, desde los primeros grados escolares, no supone quitar protagonismo a la lengua escrita, por el contrario, es una forma de enriquecer la lectura multimodal. Como afirma Kress (2000), el desafío de la lectura es vincular elementos lingüísticos con elementos no lingüísticos. Esta perspectiva multimodal se complementa con los nuevos estudios de literacidad, los cuales se enfatizan en la lectura como práctica social porque cobra sentido en contextos reales y no es exclusividad del ámbito educativo (Street, 1984). De esta manera, el aprendizaje de la lectura suele darse en los niños desde su edad infantil; incluso, antes de ser escolarizados y conocer el código alfabético, los niños interactúan con las imágenes a través de los dibujos y la televisión, acercándose a una lectura de la realidad desde su propia experiencia.

La investigación opta por el cómic, ya que como plantea Rodríguez (1998) "[...] el sujeto que lo lee, puede adaptar el ritmo de lectura -y por tanto de análisis- a sus propio ritmo de decodificación, sin sentirse condicionado por una imposición temporal exterior, como puede ser el caso del cine o la televisión" (p. 7). Por consiguiente, el cómic es utilizado en el trabajo investigativo como una experiencia didáctica para fortalecer la enseñanza de la lectura y el aprendizaje orientado hacia la comprensión y producción de otros lenguajes. Esto se evidenció durante el desarrollo de la experiencia lectora, ya que se presentó una correspondencia entre la teoría y la práctica sobre las diversas funciones que tienen los cómics, entre ellas, entretener y divertir, ser un medio de comunicación que representa la cultura y las necesidades sociales, tener una buena aceptación por la población infantil y presentar una estructura secuencial de imágenes útil para la lectura de signos verbales y no verbales.

Afirmar que los textos de cómics son una representación de la cultura y el contexto, es un hecho perceptible durante la sistematización de la experiencia de lectura y el análisis de los intercambios orales entre la docente y los estudiantes, puesto que la construcción de sentido de lo leído se realizó a partir de las vivencias familiares, escolares y sociales que han tenido los niños. Así pues, el cómic se relaciona con las prácticas de lectura vernáculas sobre los nuevos estudios de literacidad porque pertenecen a la cultura popular e involucran la emocionalidad del lector (Barton y Hamilton, 1998). Además, la lectura de cómics es una experiencia que refleja la cotidianidad y requiere para su comprensión un proceso complejo de aprendizaje.

Esta es una razón más para que la presente investigación se aborde desde la perspectiva semiótica, pues esta se enfoca en el estudio de todos los fenómenos culturales como procesos de comunicación (Eco, 1986), es decir, reconoce la naturaleza, las cualidades del texto icónico y la forma de entenderlo. La experiencia de lectura de cómics ejemplifica esta afirmación, ya que más allá de la estructura sintáctica de estos textos la finalidad fue darle sentido a la función ideológica, cultural y social que representan al conjugarse sus elementos icónicos y verbales. De esta manera, el propósito de abordar la lectura de cómics desde la perspectiva semiótica es el de orientar el carácter pedagógico y didáctico hacia la comprensión de la realidad.

Las políticas educativas también ven la necesidad de abordar la lectura desde el campo semiótico como lo evidencian los Lineamientos curriculares para el área de Lengua Castellana, propuestos por el Ministerio de Educación Nacional (1998), los cuales plantean que la lectura es un proceso significativo y semiótico cultural e históricamente situado, donde se da apertura al sistema de significación verbal y no verbal en todos los grados escolares. De igual manera, los Estándares básicos en competencias de lenguaje (MEN, 2003) comprenden como eje básico de aprendizaje los "medios de comunicación y otros sistemas simbólicos", que hacen énfasis en la comprensión de la información que circula a través de sistemas de comunicación no verbal. Esto ratifica la importancia de resignificar la práctica pedagógica por parte de los docentes sobre los procesos de enseñanza y 
aprendizaje de la lectura que se desarrollan con las nuevas formas de representación; ya que se tienen no solo más sino diversas cosas que leer, numerosos textos que no solo referencian lo escrito sino la extensión de otros lenguajes, ya sean verbales o no verbales.

Esta necesidad no se evidencia solo en el orden nacional; también internacionalmente entidades gubernamentales y no gubernamentales como la Organización de las Naciones Unidas para la Educación, la Ciencia y la Cultura (Unesco); la Comisión Europea; el Consejo de Europa; la Alianza de Civilizaciones; la Organización Islámica para la Educación, la Ciencia y la Cultura (ISESCO); la Secretaría General Iberoamericana (SEGIB); la Liga de los Estados Árabes; el Centro Internacional de Intercambio de Información sobre Niños, Jóvenes y Medios de Comunicación, de Nordicom, se interesan en responsabilizar a la escuela con los procesos de alfabetización visual para aumentar la concientización sobre la función de los medios de comunicación y los audiovisuales, con el fin de promover competencias interpretativas visuales que permitan a los espectadores una lectura crítica de la información recibida.

\section{EXPERIENCIA DE LECTURA DE IMÁGENES EN LOS PRIMEROS GRADOS ESCOLARES}

Reconocer el valor que tiene la imagen en la época actual implica conocer su origen y la evolución que ha tenido a lo largo de la historia del hombre, ya que es una de las actividades humanas más antiguas que se ha caracterizado por expresar la realidad y plasmar alguna época específica con elementos propios de su lenguaje². Según Kress (2003), de la hegemonía de la escritura se va a pasar a la hegemonía de la imagen; por tanto, las características del signo de la imagen como el punto, la línea, el color y la luz, la han convertido en uno de los principales lenguajes para documentar la realidad y los factores sociales desde épocas antiguas hasta llegar a clasificaciones actuales como la fotografía, el cine, el cómic y la televisión.
Como ya se mencionó, la imagen representa aspectos sociales y culturales de una comunidad, por eso es pertinente cuestionar el papel pedagógico que cumple la lectura de imágenes en el ámbito escolar y la relación con la comprensión de la realidad, ya que como lo plantea Barton (1994), el aprendizaje de la lectura es continuo en la vida de las personas, inicia antes de la escuela y sigue aunque esta termina. Por consiguiente, es importante que la educación reconozca que el proceso de aprendizaje de la lectura de imágenes va más allá de una práctica de percepción; este consiste en la significación y la construcción de nuevos saberes a partir de la contextualización de los signos icónicos.

Asumir prácticas pedagógicas que desarrollen experiencias de lectura de imágenes requiere de la competencia docente, es decir, del conocimiento teórico, pedagógico y didáctico, puesto que no hay aprendizaje sin enseñanza. Uno de estos elementos teóricos los señala Gombrich (1987) cuando plantea que "una correcta lectura de imágenes se rige por tres variables: el código, el texto y el contexto" (p. 133). En la estructura del código entra la clasificación de las imágenes fijas o en movimiento ${ }^{3}$ que no tienen un tratamiento de análisis igual, incluso las imágenes que pertenecen al mismo grupo de clasificación presentan diversas funciones sociales.

Otra perspectiva es la que expone Lomas (1991), quien manifiesta que en el proceso de lectura de imágenes un texto icónico actúa como un artefacto cultural encauzado por un conjunto de procesos sintácticos, semánticos y pragmáticos.

2 La primera que se conoce evoca la pintura rupestre, en la que se elaboraban dibujos prehistóricos en las cuevas o cavernas; más adelante esos dibujos se convirtieron en arte pictórico, el cual reflejaba la cultura a través de escenas de su cotidianidad como una manera de representación de su existencia; así cada periodo trae consigo nuevos estilos artísticos que la llevan a otorgarle su propio lenguaje.

3 Las imágenes en movimiento son las que producen la ilusión de movimiento. En esta clasificación entra el cine, la televisión, los videos, entre otros. Las imágenes fijas se caracterizan porque no se mueven, pueden ser únicas como la fotografía, el dibujo, la pintura; o múltiples como el cómic, novelas gráficas, libro álbum. 
[...] todo lenguaje se rige por reglas de orden sintáctico (que determinan las relaciones entre signos), reglas de orden semántico (que estructuran las relaciones entre los signos y lo que denotan) y reglas de orden pragmático (que condicionan las relaciones entre los signos y los usuarios) (p. 1).

De ello resulta una relación entre estos dos estudios realizados en este campo y se enfocan en una experiencia de lectura de imágenes en la cual no se observan los signos icónicos como elementos independientes; por el contrario, es una representación armónica de un conjunto de signos que genera una significación contextualizada.

A estos aspectos se añaden los niveles de la lectura de imágenes (Aparici y García, 1998), propuesta teórica que asume esta investigación durante la experiencia de lectura y posteriormente, en la etapa de reconstrucción y análisis de la experiencia. Esta elección se realiza porque a través de estos niveles es posible desarrollar un trabajo pedagógico de enseñanza de lectura de imágenes desde lo objetivo y lo subjetivo, la relación de estructura y contenido visual enmarcado en el contexto social y cultural.

- Nivel denotativo: sobresale la enumeración y descripción detallada que realiza el lector de cada uno de los signos que componen la imagen, sin tener en cuenta otras valoraciones de la representación gráfica, es decir, una lectura literal de lo que se ve en la imagen. En este nivel la imagen fija cuenta con elementos como el punto, la línea, la luz y el color, los cuales se utilizan para reconocer la estructura icónica de los personajes, espacio y tiempo.

- Nivel connotativo: se organiza en función de la experiencia previa de cada sujeto dando cabida al análisis de los mensajes ocultos que subyacen en una imagen; así, este texto icónico puede dar respuesta a diversos significados que se logran extraer en la medida en que se contextualice. Como afirman Aparici y García (1998), "es necesario contrastar la imagen analizada con su referente real" ( $p$. 102). Además, en este nivel se vinculan la expresión de las emociones y sentimientos que le produce la imagen al lector, por eso se considera como una lectura subjetiva.

De estas referencias se infiere que la experiencia de lectura de imágenes en los primeros años escolares demanda del lector complejas habilidades visuales e intelectuales que el niño es capaz de completar. Al respecto, Arnheim (1989, citado por Arizpe y Morag, 2004) plantea que "la intuición perceptual es la forma primaria en que la mente explora y concibe el mundo. Yo lo Ilamo concepto perceptual. [...] La mente infantil adquiere así sus primeros 'conceptos intelectuales'” (p. 28). Estos conceptos intelectuales que el niño ha aprendido por la percepción y la experiencia diaria son activados cuando, en escenarios como el escolar, se desarrollan procesos de enseñanza en contextos reales y significativos.

\section{LENGUAJES MULTIMODALES, UNA EXPERIENCIA DE LECTURA DE CÓMICS EN NIÑOS DE PRIMARIA}

Para fines de delimitación de la presente investigación se selecciona el cómic, que entra en la clasificación de imagen fija múltiple ${ }^{4}$, ya que favorece experiencias de lectura donde se involucran diversos aprendizajes como la secuencialidad, la narración, la comunicación, complemento entre el código verbal y no verbal, conocimiento de la cultura y reforzamiento de valores. El manejo de textos de imágenes como el cómic contribuyen en los procesos de enseñanza y aprendizaje al enriquecer el campo disciplinar del lenguaje a través de nuevas experiencias de lectura donde convergen diferentes modos de representar y significar la

4 Según Zamora (2006), una imagen múltiple constituye textos visuales compuestos por una secuencia de imágenes. 
realidad, es una manera de introducir los lenguajes multimodales desde los primeros grados escolares.

\section{Lectura multimodal}

La multimodalidad, como lo señalan Kress y Van Leeuwen (2001), es "el uso de varios modos semióticos en el diseño de un evento o producto semiótico, así como la particular forma en la que estos modos se combinan" (p. 12). Este planteamiento sustenta la perspectiva semiótica que adoptó la investigación; esta lectura se basa en el sentido que se le da al signo en relación con el contexto social, al desarrollar procesos que involucran la forma como se producen, circulan y comprenden los textos icónicos en la cultura. Por consiguiente, es necesario involucrar los textos multimodales en la enseñanza de la lectura como un aprendizaje fundamental desde los primeros años escolares, debido a que el lenguaje verbal cede su dominio para que otros lenguajes a través de sus diversas expresiones participen en la construcción de sentido de los textos y la configuración de la realidad.

Los textos multimodales se encuentran en la primera página de un periódico o incluso en las páginas de los libros escolares, como lo explica Van Dijk (2000): "Una profusión de imágenes, colores y titulares llamativos caracterizan a los que antes eran periódicos en blanco y negro uniformemente cubiertos por caracteres impresos. Lo mismo cabe decir de los libros de texto de ciencia, de historia o de geografía (p. 388).

Kress y Van Leeuwen (2001) también reconocen los textos multimodales a aquellos que incluyen más de un recurso para significar (fórmulas, fotografías, dibujos, mapas, lengua escrita, etc.), independiente del medio (cara a cara, impreso o digital) en el cual se distribuya. Asumir prácticas pedagógicas sobre estas nuevas formas de leer o los nuevos estudios de litreacidad (Kress, 2003) implica reconocer que el significado no solo se encuentra en el texto o el lector, por el contrario, los aspectos sociales del contexto permiten la comprensión de estos textos que forman parte de la cultura.

\section{Multimodalidad del cómic en la formación de niños lectores}

Desarrollar una experiencia de lectura de cómics requiere una claridad conceptual sobre este tipo de texto e identificar los elementos que lo categorizan como un texto multimodal. Por esta razón, las definiciones que se exponen a continuación son pertinentes para el proceso de investigación. Según Eco (1999), el cómic, también denominado historieta o tebeo, "es un producto cultural, ordenado desde arriba, y funciona según toda mecánica de la persuasión oculta, presuponiendo en el receptor una postura de evasión que estimula de inmediato las veleidades paternalistas de los organizadores" (p. 257). Así, desde sus orígenes, el cómic se ha caracterizado por ser un producto de la época industrial, y catalogado, desde ese entonces, como un texto de la cultura que está al alcance de toda la comunidad, bajo la denominación cultura de masas.

En la misma línea se encuentra Zunzunegui (1989) quien argumenta que el cómic es uno de los medios expresivos más singulares de la cultura contemporánea y que hablar de cómics crea una relación obligatoria con los mass media, es decir, un medio de comunicación que llega a un buen número de personas. Por eso, Eisner (1996) plantea que "la historieta es un medio único en su género, con estructura y personalidad propias, que puede tratar cualquier tema, por intrincado que sea" (p. 5). De esta manera, la lectura de cómics desde los primeros grados escolares es propicia en los procesos de enseñanza y aprendizaje ya que media en la construcción de la subjetividad, la cual está influenciada por la sociedad.

En ese sentido, Larrosa (2003) señala que "pensar la lectura como formación implica pensarla como una actividad que tiene que ver con la subjetividad del lector: no solo con lo que el lector sabe sino con lo que es" (p. 25). Por tanto, en este proceso investigativo no se busca una lectura donde se identifica la estructura del cómic, por el contrario, una experiencia donde los niños puedan 
manipular el texto, evidenciar sentimientos, resolver preguntas que los inquietan, ir descubriendo el comportamiento y las acciones como lector, además de usar la sintaxis de estos textos para su comprensión.

Otra perspectiva útil para esta investigación es la que caracteriza el cómic como un texto multimodal porque combina en su superestructura elementos verbales y no verbales. Al respecto, Gubern (1981) argumenta que "el cómic es una estructura narrativa formada por la secuencia progresiva de pictogramas en los cuales pueden integrarse elementos de escritura fonética" (p. 14), es decir, un sistema de significación que cuenta una historia por medio de una secuencia de dibujos y textos escritos interrelacionados. Sin embargo, el cómic por sí solo es un mecanismo perezoso (Eco, 1981). Por ello, para esta experiencia lectora la construcción de sentido del cómic se logra a partir de la relación que establece el lector con el texto y a través de la aplicación de estrategias de lectura $^{5}$ como la activación de conocimientos previos, el uso de predicciones, la interrogación del texto y el monitoreo de los avances y dificultades de la lectura.

Señalar la secuencia narrativa del cómic implica especificar la estructura en la que se organiza, la cual consta de una serie de unidades dotadas de significado que guardan relación con el código lingüístico. Las primeras de ellas, las macrounidades significativas, constituyen el modelo o esqueleto que caracteriza al cómic; las segundas, unidades significativas, constituidas por las viñetas, las cuales son la unidad de significado del cómic; y las terceras corresponden a las microunidades significativas, donde se encuentran todos los elementos que componen la viñeta como el encuadre, los planos, los ángulos, los formatos, el color, los bocadillos y los signos convencionales conformados por la metáfora

5 Isabel Solé (1992) plantea que "enseñar a leer no es fácil. La lectura es un proceso complejo, requiere una intervención antes, durante y después. Y también plantearse la relación entre leer, comprender y aprender" (p. 18). visual, las figuras o líneas cinéticas (Gubern, 1981, pp. 110 -111). La perspectiva de este autor en alusión a los elementos del cómic se asume como propuesta para la presente investigación.

\section{ASPECTOS METODOLÓGICOS DE LA INVESTIGACIÓN}

La ruta metodológica de este trabajo investigativo parte del enfoque cualitativo que, según Taylor y Bogdan (1986), es considerado como "aquel que produce datos descriptivos: las propias palabras de las personas, habladas o escritas, y la conducta observable" (p. 20), caracterizándose por centrar su indagación en aquellos contextos naturales que se encuentran en su estado original sin llegar a tener modificaciones por los intereses del investigador. A partir de este enfoque, la investigación se basó en el diseño de sistematización de experiencias como obtención de conocimiento, ya que se reflexionó y analizó la práctica educativa en torno a la experiencia de la lectura de cómics desde una visión teórica, pedagógica y didáctica. Así como lo señala Jara (2001), este tipo de investigación plantea una reflexión crítica de la experiencia y una construcción de conocimiento a partir de ella.

La investigación se sistematizó en cuatro fases: diseño de la experiencia, desarrollo, reconstrucción y, por último, análisis, interpretación y conclusiones.

\section{a) Fase de diseño de la experiencia}

Esta fase inició con la definición del objetivo investigativo que orientó el proceso de la sistematización, mencionado en los primeros apartados de este artículo, que hace referencia a la enseñanza de experiencias de lectura de imágenes como el cómic para construir una lectura con sentido en primer grado de básica primaria. Tras la identificación del objetivo se establecieron las siguientes categorías deductivas que orientaron la progresividad de la experiencia, 
lectura de imágenes, el cómic y formación de niños lectores.

En esta etapa también se identifican los actores que forman parte de la experiencia, los cuales estaban conformados por 38 estudiantes de género mixto del grado primero de básica primaria de un colegio público de Bogotá, con edades entre los 6 y 7 años. El grupo se caracterizaba por tener un aprendizaje básico del código alfabético, manifestar interés por la lectura de cuentos en voz alta y usar los dibujos como representación de sus sentimientos.

La estrategia de intervención seleccionada para la experiencia de lectura de imágenes fue el taller pedagógico ${ }^{6}$, ya que permite la planeación y proyección de los aspectos investigativos, pedagógicos y didácticos con una notoria intencionalidad. Además, como lo sugiere Rodríguez (2012) "El taller constituye una estrategia válida para la conformación de un corpus significativo a través del cual se pueden interpretar las distintas categorías analíticas implicadas en la investigación" (p. 35)
Para llevar a cabo la experiencia lectora con los estudiantes de grado primero, se planeó una secuencia de seis talleres pedagógicos organizados por etapas, así: dos de sensibilización, tres de fundamentación y uno de cierre, con propósitos particulares que apuntaron progresivamente al desarrollo de cada una de las categorías deductivas. Esta estrategia metodológica se empleó durante toda la intervención para recolectar, sistematizar y analizar el corpus, relacionando la teoría y la práctica pedagógica de la docente.

\section{b) Fase de desarrollo de la experiencia}

El taller pedagógico se caracterizó por ser participativo, al promover espacios abiertos de interacción y favorecer la reflexión conjunta; también fue sistémico porque permitió, de forma permanente, la autoevaluación y ajustes del proceso. Estas dos características fueron fundamentales para el proceso, ya que después de finalizar la aplicación cada taller fue sometido a la sistematización con el fin de evaluar los resultados y tener criterios para ajustar o elaborar el siguiente taller. Cada uno de los talleres se organizó en tres momentos (Tabla 1).

Tabla 1. Los seis talleres dieron respuesta al propósito investigativo, y también a los objetivos pedagógicos y didácticos propuestos para la intervención

\begin{tabular}{llllll}
\hline \multicolumn{2}{c}{ Etapa de sensibilización } & \multicolumn{2}{c}{ Etapa de fundamentación } & \multicolumn{2}{c}{ Etapa de cierre } \\
\hline Taller No. $\mathbf{1}$ & Taller No. $\mathbf{2}$ & Taller No. $\mathbf{3}$ & Taller No. $\mathbf{4}$ & Taller No. $\mathbf{5}$ & Taller No. $\mathbf{6}$ \\
\hline Tumaquito. & Leo mi entorno. & Historias cómicas. & Comiaventuras. & $\begin{array}{l}\text { Mi mundo en } \\
\text { viñetas. }\end{array}$ & $\begin{array}{l}\text { Lecturas cómicas } \\
\text { en familia. }\end{array}$
\end{tabular}

Momentos de cada taller

Fase inicial: presentación del objetivo del taller y planeación de actividades introductorias que propician un escenario de intercambio de conocimientos previos sobre la lectura de imágenes.

El proceso de metacognición

Fase central: actividades progresivas centradas en la experiencia de lectura de imágenes, específicamente del cómic, para desarrollar la sensibilización con la imagen y la construcción de sentido que estuvo presente de manera transversal se lee de ella. en todas las fases.

Fase de cierre: retroalimentar y evaluar los aprendizajes.

Fuente: elaboración propia.

6 Ander-Egg (1999) y Rodríguez (2012) coinciden en la multifuncionalidad del taller desde tres visiones operativas: en los procesos de enseñanza, de aprendizaje y en el plano investigativo. 
Las fases 3 y 4 del diseño de sistematización, correspondientes a reconstrucción, análisis, interpretación y conclusiones de la experiencia, se presentan en las secciones de análisis y conclusiones.

\section{ANÁLISIS DE RESULTADOS}

Los registros y corpus que se presentan en el documento forman parte de la recolección de datos de la investigación ${ }^{7}$ y se emplean para fundamentar el análisis y resultados entre las categorías deductivas. La finalidad de este apartado es evidenciar los aprendizajes de los estudiantes vinculados a la experiencia de lectura del cómic y la construcción de sentido que resulta de la interacción con lo leído, en relación con la teoría dispuesta para validarse en la práctica pedagógica. Al respecto, De Tezanos (2006) denomina esta correspondencia como saber pedagógico, el cual "emerge de la reflexión sistemática de la práctica" (p. 52). Es decir, la obtención de conocimiento que referencia el diseño metodológico surge de la reconstrucción de la experiencia lectora al validarla con la teoría proyectada.

\section{Lectura de imágenes en la escuela: un acercamiento a la sensibilización visual y a la formación de lectores}

El análisis de los datos que se exponen en este primer momento corresponde a la implementación de los dos talleres de la etapa de sensibilización, los cuales tenían como propósito realizar un primer acercamiento de los estudiantes a la lectura de imágenes e identificar el perfil lector de los niños en relación con los textos icónicos.

Desde los primeros intercambios orales entre la docente y los estudiantes se evidencia una tendencia por el reconocimiento de la lectura lingüística, es decir, los estudiantes en sus expresiones y prácticas de lectura no son conscientes del valor comunicativo y semántico que tiene el código no verbal. El siguiente registro refleja esta postura, después de realizar una actividad donde se privilegió la observación y percepción de imágenes.

Docente investigadora (DI): ¿Los dibujos se pueden leer?

Voz grupal de los estudiantes (E): No.

DI: Entonces, ¿qué se puede leer?

E5: Las letras. $\quad$ E16: Las palabras. E31: Los títulos

E11: Los dibujos que uno tiene ahí en la hoja pueden decir cosas.

Registro de clase oral

Esto permite inferir que la enseñanza de la lectura en los primeros grados se ha enfatizado en el aprendizaje del código alfabético, razón por la cual la docente reflexiona y valida la perspectiva de lectura que aborda con sus estudiantes, al incursionar en experiencias de lectura de imágenes donde se privilegie la construcción de sentido y el acercamiento a la realidad a través de las representaciones icónicas.

7 El corpus de la investigación se obtuvo durante el periodo 2014-2015, a través de grabaciones, registros escriturales, observaciones y diario de campo de la docente.
El siguiente planteamiento de Lazoti Fontana (1983, citado por Lomas, 1991) corresponde a lo vivenciado en la práctica pedagógica:

[...] los alumnos no se dan cuenta de las múltiples comunicaciones visuales presentes en su vida, puesto que están acostumbrados a considerar como información sólo lo que les llega por medio de la palabra. Por tanto, sensibilizarlos para captar los mensajes visuales que cotidianamente nos envían información representa un primer momento educativo necesario (p. 151). 
Esta reflexión teórica se relaciona con una de las actividades de la primera etapa del taller pedagógico, la cual consistió en una experiencia de lectura a partir de las propias representaciones de los estudiantes, cuyos propósitos eran la sensibilización visual y la identificación del nivel de análisis de la lectura de imágenes en el que se encontraban los niños. La actividad fue orientada por la docente para que los estudiantes elaboraran un dibujo donde expresaran sus gustos, emociones y sentimientos; posteriormente cada niño hizo lectura de sus imágenes a sus compañeros.

En las Figuras 1 y 2 se presentan los resultados del análisis de los registros de 32 estudiantes que participaron de la actividad.

La Figura 1, que hace referencia a la producción gráfica, evidencia que más de la mitad del grupo de estudiantes combinó el código lingüístico con el código icónico para darle una explicación a la imagen, esto ratifica el desconocimiento que tienen los estudiantes ante el valor semántico y pragmático del código no verbal, pues necesitan reforzar la elaboración gráfica de la imagen con el uso del lenguaje verbal.

La Figura 2 corresponde a la lectura que cada niño hizo de su propia producción gráfica ante el grupo de compañeros. Un primer análisis muestra que la lectura describe lo plasmado gráficamente, "equivalencia entre el signo gráfico convencionalizado y el rasgo pertinente del código de reconocimiento" (Eco, 1986, p. 75), es decir, que los dibujos de todos los niños son signos que reflejan una realidad reconocida convencionalmente. Otro momento del análisis fueron los niveles de lectura de imágenes en los cuales hay una tendencia por el nivel denotativo, ya que los estudiantes realizaron una lectura describiendo y listando los elementos del dibujo y justificando su elección por gusto y experiencias previas.

E18: Es que me dibujé ayudando a un niño.

D: ¿Por qué dibujaste eso?

E18: ¿Porque a mí me gusta ayudar mucho?

E7: Es de Rapunzel, se llama Rapunzel.

D: ¿Por qué hiciste a Rapunzel?

E7: Hice a Rapunzel saliendo de la torre con alguien que va a la torre y él llevó una sillita para rescatarla.

D: ¿Por qué escogiste a Rapunzel para tu dibujo?

E7: ¿Porque me gusta y la veo mucho en televisión?

Registro de clase oral

La otra parte del grupo de estudiantes se acerca a una lectura connotativa ya que realizan abstracción e inferencias de su representación gráfica, le dan sentido a la imagen extrayendo elementos explícitos.

E21: Yo quisiera ser ganadora de la vida, por eso hice este dibujo, cuando sea grande voy a ganar con toda.

E24: ...Me gustan las motos porque son muy rápidas y los espías porque son secretos, ellos siempre están cubiertos. 


\section{Producción de imágenes}

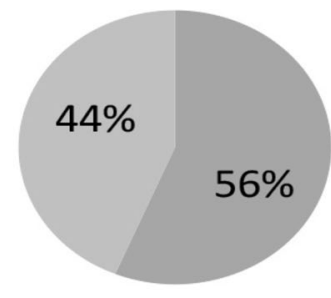

Lenguaje verbal y no verbal

Lenguaje no verbal

Figura 1. La mayoría de dibujos combina el lenguaje no verbal con el lenguaje verbal; los otros usan solo el lenguaje no verbal para su representación.

Fuente: elaboración propia.

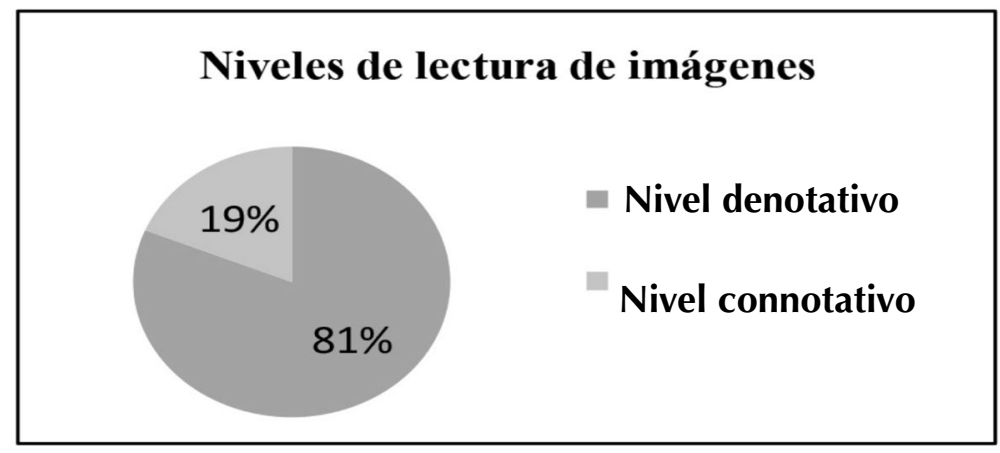

Figura 2. El nivel denotativo presenta una descripción de los elementos de la imagen y el connotativo realiza una construcción de sentido fuera de los elementos explícitos de la imagen.

Fuente: elaboración propia.

De este resultado se infiere la dificultad que presentan los estudiantes para construir el significado contextualizado de la imagen, puesto que se limitan a aspectos literales del signo.

Este análisis no resulta solo de una lectura técnica de la imagen bajo constructos teóricos sino que requiere de aspectos pedagógicos y didácticos que surgen en la práctica. Del discernimiento de estos elementos conjugados en la práctica pedagógica se genera nuevo conocimiento, es decir, saber pedagógico, que permite consolidar la experiencia de lectura de imágenes hacia la formación de lectores. Por esta razón, durante la sistematización de los talleres pedagógicos de la etapa de sensibilización la docente reflexiona acerca de la elaboración de consignas estructuradas, la formulación de preguntas que conlleven a lo inferencial, la articulación de los conocimientos previos con los nuevos conocimientos, la vinculación del proceso de metacognición y la posibilidad de favorecer el aprendizaje del lenguaje no verbal con el verbal, para la planeación e intervención de los siguientes talleres.

\section{La experiencia de lectura de cómics, un camino para la formación de niños lectores}

De la sistematización de la etapa de sensibilización se reconoce un perfil lector que se caracteriza por los siguientes aspectos e identifica al grupo de estudiantes: se privilegia el aprendizaje del código alfabético, ya que la enseñanza de la 
lectura se enfatiza en la decodificación silábica; hay un acercamiento predominante por los textos narrativos a través de la lectura de cuentos o historias, lo cual posibilita la identificación de los elementos del género narrativo: personajes, espacio y tiempo; el uso inconsciente de algunas estrategia de lectura como predecir a partir del título o imágenes, releer y parafrasear lo leído a alguien; y no consideran pertinente la lectura de signos no verbales en su contexto escolar.

A partir de este perfil lector se valoran los avances que tienen los estudiantes durante la experiencia de lectura de cómics y también se emplea como un indicador para la planeación y seguimiento de los talleres pedagógicos en la etapa de fundamentación y de cierre.
El análisis que se expone en los siguientes apartados corresponde a la experiencia de lectura del cómic desarrollada en los talleres de fundamentación y de cierre. En la etapa de fundamentación se inicia con la indagación de conocimientos previos que tienen los estudiantes sobre el cómic; aquí se evidencia el desconocimiento por estos textos y la poca interacción con lecturas de esta tipología. Estos hallazgos se corroboran cuando los niños realizan el primer acercamiento de lectura de cómics, puesto que enfatizan en la decodificación del código verbal de los bocadillos y obvian el significado que genera la representación icónica. Como se ejemplifica en el registro.

DI: Vamos a realizar la lectura, cada uno con su texto.

E8: Yo ya voy en Hola.

E34: Yo no sé leer.

DI: Para leer no hay necesidad de que te detengas solo en las letras, miras las imágenes, E34, y lee las imágenes, ellas también se pueden leer y nos representan algo.

E8: Profe, ¿aquí cómo se lee?

DI: Dice: "Mmmmm, mmmmm".

E8: Profe, ¿aquí qué dice?

DI: "Oh".

E14: Hola, hola. Sí, sí, claro. Ah ya. Ah ya. Oh claro. Claro.

Registro de clase oral

Estas acciones de los actores en la práctica pedagógica forman parte de la reflexión docente, pues aunque la imagen es un lenguaje dominante en la actualidad, en la escuela se elude su enseñanza. Luego de la sistematización de esta experiencia se realizan reajustes a los talleres de fundamentación lo que conlleva a realizar la reprogramación de los textos partiendo de un cómic silente, sin palabras, con el fin de continuar el proceso de sensibilización y dar paso a la construcción de sentido a través de la contextualización de los elementos del cómic y de la imagen. En los siguientes talleres se involucraron experiencias lectoras de cómics con diálogos para que el complemento entre el lenguaje verbal y no verbal favoreciera la comprensión de los textos, además se fueron complejizando las macrounidades, las unidades y las microunidades significativas de esta tipología. Esta experiencia se diversificó con estrategias de lectura, la expresión de sentimientos, la emisión de juicios sobre el texto, intercambios orales y la reconstrucción de la experiencia que fueron constituyendo las actitudes y comportamiento del lector.

Los siguientes textos de Tumaco ${ }^{8}$ (Figura 3) y Quemados por el dragón ${ }^{9}$ (Figura 4) son un ejemplo de las lecturas que hicieron parte de esta experiencia, en la etapa de fundamentación de los talleres pedagógicos.

8 Publicado por la Editorial Rey Naranjo en el año 2014, el guion está escrito por Óscar Pantoja y los dibujos por el ilustrador Jim Pluk.

9 Cómic extraído del libro Un hombre con sombrero, del escritor argentino Gustavo Roldán, publicado por la Editorial Dibbuks en 2010. 


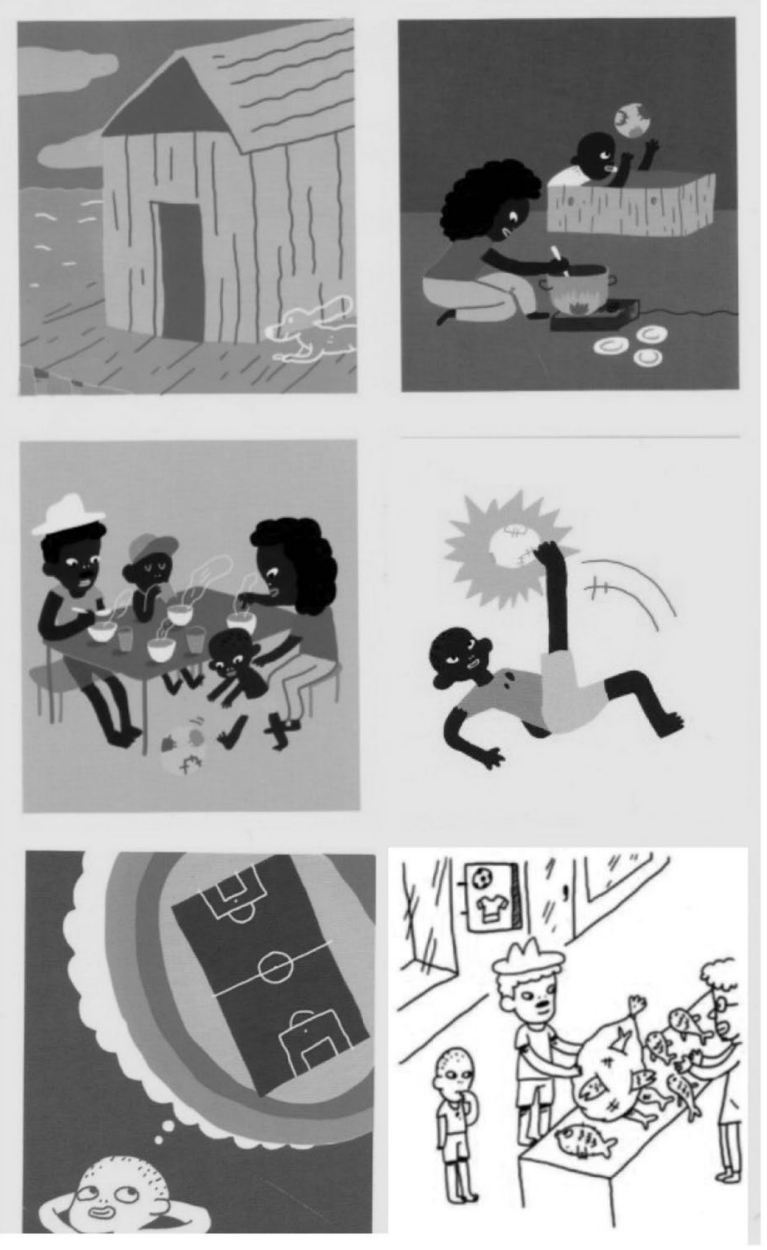

Figura 3. Lectura de Tumaco realizada en el taller 3 de la etapa de fundamentación.

Fuente: elaboración propia.

A continuación se exponen, de forma paralela entre los dos textos, algunos elementos de carácter teórico, pedagógico y didáctico que se involucraron en la experiencia de lectura. La

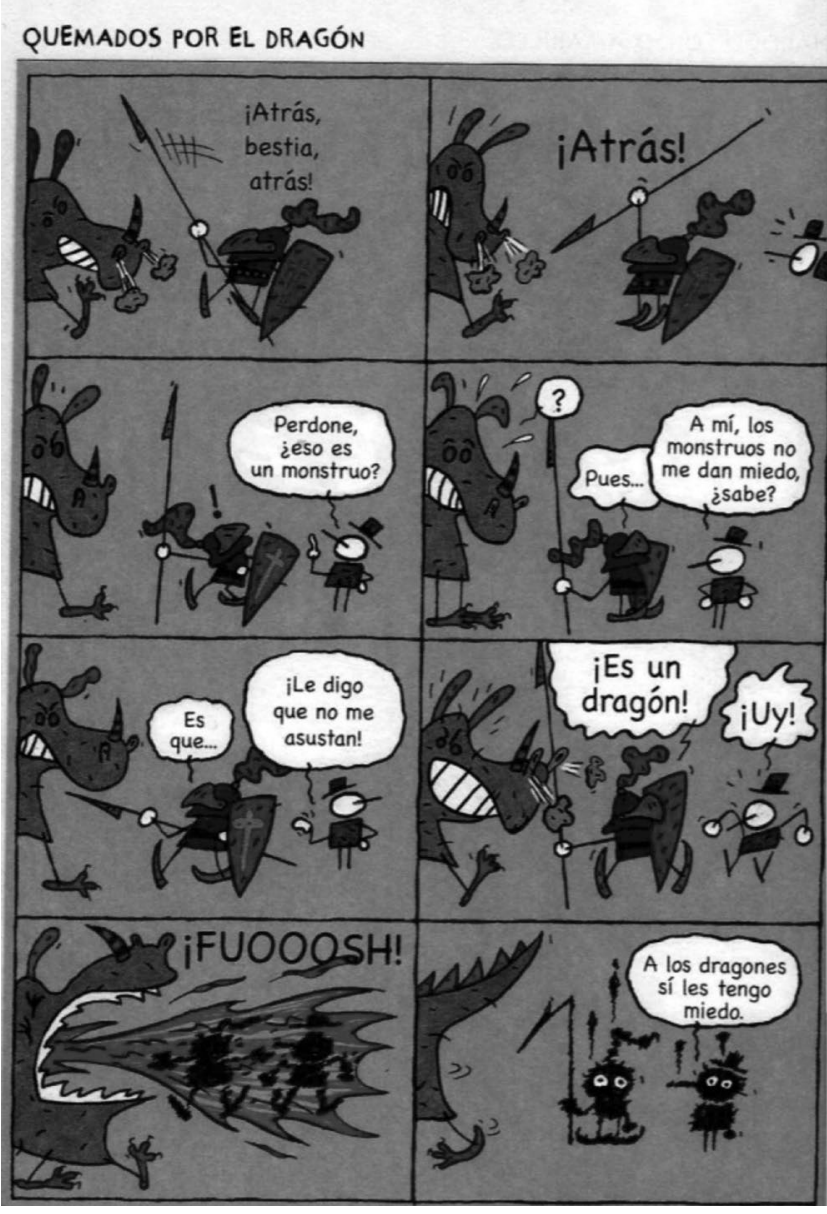

Figura 4. Lectura realizada en el taller 5 de la etapa de fundamentación.

Fuente: elaboración propia.

docente inició con la orientación de características de las macrounidades significativas, es decir, del esqueleto del cómic, ya que era fundamental reconocer la tipología textual que se leería.

\section{Tumaco}

DI: ¿Qué características tiene este texto?

E9: Ya lo habíamos visto, un cómic.

E23: No tiene letras.

E2: Tiene muchos cuadros.

E10: Ahí está Tumaquito con los papás.

DI: Muy bien, vamos a leer un cómic silente, es decir, que no tiene letras, solo dibujos. Y esos cuadrados se llaman viñetas.

\section{Quemados por el dragón}

DI: ¿Qué tipo de texto vamos a leer?

E9: Un cómic.

DI: ¿Cómo lo sabes?

E9: Tiene siete viñetas.

E12: Tiene globos con letras.

E25: No es silente porque tiene letras.

\section{Registro de clase oral}


Después de identificar la tipología textual se estableció grupalmente el propósito de la lectura; se realizaron predicciones a partir del título y se indagaron los conocimientos previos de los estudiantes. Estas estrategias de lectura orientaron el sentido de la experiencia.

\begin{tabular}{|c|c|}
\hline Tumaco & Quemados por el dragón \\
\hline DI: Vamos a definir para qué vamos a leer este cómic. & DI: ¿Qué propósito va a tener esta lectura? \\
\hline E30: Para conocer a Tumaquito. & E25: Conocer otro cómic. \\
\hline E5: Para aprender. & E17: Aprender a leer imágenes. \\
\hline DI: ¿De qué tratará Tumaco? & DI: ¿De qué tratará Quemados por el dragón? \\
\hline E26: Del niño que vive en Tumaquito. & E22: Que un dragón quemó a alguien. \\
\hline E16: Profe, nos va a contar cómo es Tumaco. & $\begin{array}{l}\text { E34: Yo, yo, que alguien se murió porque un dragón lo mató } \\
\text { cuando echó fuego por la boca. }\end{array}$ \\
\hline DI: ¿Qué sabemos sobre Tumaco? & DI: ¿Qué sabemos sobre los dragones? \\
\hline E28: Tumaco es un niño que le decimos de cariño Tumaquito. & E10: Los dragones no existieron. \\
\hline \multirow{2}{*}{$\begin{array}{l}\text { E10: No, Tumaquito no existe. Tumaco es una ciudad que } \\
\text { tiene mar, ¿cierto, profe? }\end{array}$} & E16: Sí existían, antes de los dinosaurios. \\
\hline & E9: Eran como en Dragon Ball. \\
\hline & \\
\hline
\end{tabular}

Estas estrategias no las plantea la teoría de la lectura de imágenes o de cómics, sin embargo, para la experiencia en la práctica pedagógica fueron fundamentales porque se parte del saber y de la experiencia de los estudiantes antes de enfrentarlos a conocimientos nuevos. Es el ejemplo del estudiante E9 que vincula textos de la cultura popular, el programa infantil de Dragon Ball, como referente para la construcción de conocimiento sobre los dragones. En este punto es oportuno aclarar que estas estrategias no se desarrollaron como un recetario, sino como un intercambio de saberes que se enriquecieron con el aprendizaje de los estudiantes y la mediación de la docente.

Posteriormente, se inició la lectura del cómic donde se privilegió la interrogación de textos y el monitoreo constante del aprendizaje. Este momento de la experiencia fue primordial porque la interacción que establecieron los estudiantes con el texto a través de la expresión de emociones, sentimientos, intercambio de opiniones y la emisión de juicios de valor sobre el cómic fue el canal para la construcción colectiva de hipótesis de sentido. El registro es un ejemplo de estas acciones.
Este corpus evidencia que los estudiantes establecen un intercambio de saberes en un contexto real, que les permite lograr de forma colectiva la construcción de hipótesis de sentido del texto y la comprobación de predicciones. De esta manera, comparten un diálogo sobre las representaciones sociales y culturales de su cotidianidad que también aportan a la comprensión del cómic. Por otra parte, la mediación docente a través de la pregunta, como en el caso del estudiante E9, es pertinente para que los niños sean conscientes de sus aprendizajes y reflexionen acerca de la utilidad de estos al momento de la interpretación textual.

Por último, la etapa de cierre de los talleres pedagógicos se enfocó en una experiencia de lectura con los padres de familia para que, junto con los estudiantes, una transferencia de aprendizaje sobre el proceso desarrollado en las lecturas de cómics anteriores. Esta acción pedagógica favorece la formación de lectores desde ambientes familiares, la actitud y el comportamiento del lector que aportan a la constitución de la subjetividad y de su propio yo, desde los primeros grados escolares. 


\section{Tumaco}

DI: Vamos a realizar una lectura silenciosa de las imágenes y luego compartimos lo que entendimos del texto.

E14: Tumaco tiene un hermano.

E33: Todos son negritos.

E21: Tumaco es pobre.

DI: ¿Cómo logras, E21, saber que él es pobre?

E21: Sí, miren el cuadro donde está la estufa, en el suelo.

E18: Porque viven en una casa de palos en el mar.

E5: Profe, ¿por qué Tumaco y toda su familia están descalzos?

E21: Porque son pobres.

E30: Yo tengo una amigo de Tumaco en la Fundación Amar y también es negrito.

E10: No es porque sean pobres allá todos están descalzos porque viven en el mar y se mojan los zapatos.

E7: Profe, ¿será qué son pobres porque son negritos?

E6: Eso no tiene nada que ver hay negros ricos como el presidente de los Estados Unidos.

E33: Tumaco no es pobre porque se ve feliz con su familia.

\section{Quemados por el dragón}

DI: Vamos a leer el cómic en silencio y me van a contar cómo logran entenderlo.

E37: Profe, el dragón está furioso con el señor de la flecha porque lo quiere matar. Le sale humo por la nariz y muestra sus dientes.

E25: Es un dragón raro porque tiene orejas de perro, nariz de unicornio y patas como de pollo.

E34: El que va a atacar al dragón es un soldado antiguo, es romano.

DI: ¿Cómo sabes, E34, que es un soldado romano?

E34: Porque yo los he visto en las películas y se ponen armaduras y el escudo para protegerse.

E9: ¿Y ese señor de sombrero qué hace ahí?, parece de otra época.

DI: ¿Por qué?

E9: Porque antes no se vestían así.

E18: Yo creo que el señor de sombrero está soñando y por eso ese dragón parece un monstruo.

E10: E18, y luego ¿cómo son los monstruos? Ni existen.

E18: Bueno, es un dragón todo raro, tiene hasta dientes de perro, como cuando les da rabia.

E9: Profe, ¿si ves que cuando ya los va a atacar el dragón ellos gritan?

DI: ¿Cómo sabes eso?

E9: Porque el globo es diferente, tiene puntas así como el que nos mostraste.

\section{Registro de clase oral}

Por consiguiente, la práctica pedagógica se relaciona con la afirmación de Jolibert (1998) cuando señala que leer es interrogar un texto, es decir, "corresponde a una interacción activa, curiosa, ávida, directa, entre un lector y un texto" (p. 58). Por tanto, la lectura de imágenes que se desarrolló en este proceso de investigación no se centró en un aprendizaje conceptual técnico del cómic; por el contrario, las macrounidades, las unidades y las microunidades significativas del cómic se leyeron en función de la construcción de sentido de la secuencia narrativa.

Este planteamiento surge de la experiencia vivida, ya que la teoría de la lectura de imágenes y del cómic se acopló a elementos pedagógicos y didácticos que permitieron, en primer lugar, a los estudiantes ir paso a paso en la consolidación del aprendizaje de una lectura de imágenes con sentido. En segundo lugar, la reflexión de la práctica de enseñanza de la docente ya que se propusieron y reelaboraron conocimientos alrededor de la experiencia de lectura de imágenes que no formaban parte de prácticas pedagógicas anteriores a esta experiencia. $Y$ en tercer lugar, del proceso investigativo emergieron otros aspectos teóricos como el intertexto y la producción escrita que no estaban proyectados en el estudio, pero que la experiencia fue catapultando como condición didáctica para el aprendizaje de la lectura de imágenes. 


\section{CONCLUSIONES}

Este estudio evidencia el valor que tiene la práctica pedagógica, ya que cuando el docente realiza procesos de reflexión y sistematización rigurosos sobre ella, surge conocimiento para enriquecer la enseñanza de la lectura aplicable a otras experiencias del campo del lenguaje y a otros campos del saber. De esta manera, la investigación aporta a la cualificación de la práctica educativa al favorecer la formación docente y ampliar su conocimiento a las nuevas formas de leer que enfrentan los estudiantes en la actualidad. Entonces, el saber pedagógico de la experiencia vivida permite concluir que la enseñanza de la lectura de imágenes es un aprendizaje necesario en todos los grados escolares para comprender los aspectos culturales de nuestra sociedad.

Desde esta perspectiva, la experiencia de lectura fue un proceso de aprendizaje para los estudiantes, ya que inicialmente, reconocieron y aplicaron el valor semántico y pragmático que tiene el código no verbal. En segunda instancia, emplearon las particularidades de la lectura de signos iconográficos en beneficio de la construcción de sentido del texto a partir de su experiencia y de los aspectos culturales de su realidad. A través de esta experiencia se dio inicio a su formación como lectores; además, la interacción con la lectura de cómics los fue transformando y les aportó a la configuración de su propio yo. Por eso, los nuevos saberes y la exploración de los sentimientos de los estudiantes fueron producto de la experiencia de lectura con el intercambio cultural.

Para concluir, reconocer la lectura como hecho semiótico presentó un gran valor teórico, conceptual y didáctico para esta investigación, ya que esta perspectiva no desconoce la existencia de otros códigos de la cultura, por el contrario, une la existencia de todos los códigos por ser portadores de significación y comunicación. Así, la enseñanza de la lectura de imágenes es una posibilidad para fortalecer el acercamiento de los estudiantes al aprendizaje del código alfabético, para que, como afirma Freire (1999), la lectura implique tomar conciencia de que el conocimiento se convierte en una herramienta importante para actuar sobre su propia realidad. Por tanto, el resultado de este estudio confirma la importancia de la lectura del código convencional y la construcción de sentido que propicia la lectura de imágenes, formando una acertada cooperación entre el lenguaje verbal y el no verbal.

\section{RECONOCIMIENTOS}

Este artículo es resultado de la investigación "Lectores de cómics: constructores de sentido", realizada en el marco de la Maestría en Pedagogía de la Lengua Materna de la Universidad Distrital Francisco José de Caldas.

\section{REFERENCIAS}

Ander-Egg, E. (1999). El taller: una alternativa de renovación pedagógica. Buenos Aires: Editorial Magisterio del Río de la Plata.

Aparici, R. y García, A. (1998). Lectura de imágenes. Madrid: Ed. de la Torre.

Arizpe, E. y Morag, S. (2004). Lectura de imágenes. Los niños interpretan textos visuales. México: Fondo de Cultura Económica.

Barton, D. (1994). Literacy. Oxford: Blackwell.

Barton, D. y Hamilton, M. (1998). Local Literacies: Reading and Writing in One Community. Londres: Routledge.

Cassany, D. (2009). Para ser letrados. Barcelona: Paidós.

De Tezanos, A. (2006). El maestro y su formación: tras las huellas y los imaginarios. Bogotá: Editorial Magisterio.

Eisner, W. (1996). El cómic y el arte secuencial. Barcelona: Norma Editorial.

Eco, U. (1976). Signo. Barcelona: Ed. Labor.

Eco, U. (1981). Lector in fábula. Barcelona: Lumen.

Eco, U. (1986). La estructura ausente. Introducción a la semiótica. Barcelona: Editorial Lumen. 
Eco, U. (1999). Apocalípticos e integrados, estudio sobre la cultura popular y los medios de comunicación. Barcelona: Editorial Lumen.

Freire, P. (1999). La importancia de leer y el proceso de liberación. México: Siglo XXI Editores.

García, J. (2013). Uso educativo de los cómics y herramientas para elaborarlos. Cali: Eduteka. Recuperado de: http://www.eduteka.org/comics.php

Gombrich, E. (1987). La imagen y el ojo. Madrid: Alianza Editorial.

Gubern, R. (1981). El lenguaje de los cómics. Barcelona: Península.

Jara, O. (2001). Dilemas y desafíos de la sistematización de experiencias. San José de Costa Rica: Alforja.

Jolibert, J. (1998). Interrogar y producir textos auténticos: vivencias en el aula. Providencia Santiago: Dolmen Ediciones.

Kress, G. (2000). Design and Transformation: New Theories of Meaning. En: B. Cope y M. Kalantzis (eds.). Multiliteracies: Literacy learning and the design of social futures (pp. 153-161). Londres: Routledge.

Kress, G. (2003). Literacy in the New Media Age. Londres: Routledge.

Kress, G. y Van Leeuwen, T. (2001). Multimodal discourse. The modes and media of contemporary communication. Londres: Arnold.

Larrosa, J. (2003). La experiencia de la lectura, Estudios sobre literatura y formación. México: Fondo de Cultura Económica.

Lomas, C. (1991). La imagen. Instrucciones de uso para un itinerario de la mirada. Signos, teoría y práctica de la educación, 1, 14-25.
Metz, C.; Eco, U.; Durand, J.; Péninou, G.; Morin, V.; Du Pasquier, S.; Fresnault-Deruelle, P.; Bertin, J.; Marín, L. y Schefer, J. (1972). Análisis de las imágenes. Buenos Aires: Editorial Tiempo Contemporáneo.

Ministerio de Educación Nacional (MEN) (1998) Lineamientos curriculares para el área de Lengua CasteIlana. Bogotá: Magisterio.

Ministerio de Educación Nacional (MEN) (2003). Estándares básicos en competencias de Lenguaje. Bogotá.

Rodríguez, J.L. (1988). El cómic y su utilización didáctica: los tebeos en la enseñanza. Barcelona: Gustavo Gili.

Rodríguez, M. (2012). El taller: una estrategia para aprender, enseñar e investigar. En: S. Soler. Lenguaje y Educación: perspectivas metodológicas y teóricas para su estudio (pp. 13-43). Bogotá: Doctorado Interinstitucional en Educación, Universidad Distrital Francisco José de Caldas

Street, B. (1984). Literacy in theory and practice. Nueva York: Cambridge University Press.

Solé, I. (1996). Estrategias de lectura. Barcelona: Graó.

Taylor, S. y Bogdan, R. (1986). Introducción a los métodos cualitativos de investigación. Buenos Aires: Paidós.

Van Dijk, T. (2000). El discurso como estructura y proceso. Barcelona: Gedisa.

Zamora, F. (2006). Filosofía de la imagen. Lenguaje, imagen y representación. México: Universidad Autónoma de México.

Zunzunegui, S. (1989). Pensar la imagen. Madrid: Cátedra. 